\title{
A Rheumatologist Managing Patients with Rheumatoid Arthritis: An Artisan But Also An Artist!
}

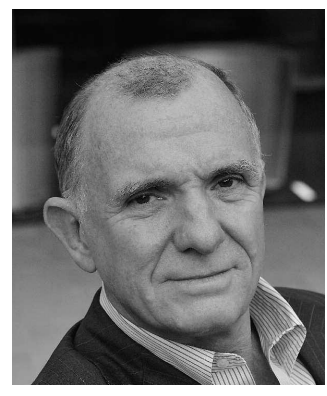

In this issue of The Journal Lonnie Pyne and colleagues report the results of an analysis aimed at evaluating the respective roles of the patient (patient's global assessment), the physician (physician's global assessment), and a composite index, the Disease Activity Score (DAS) ${ }^{1}$ in the decision for indicating and/or reinforcing a disease-modifying drug in rheumatoid arthritis (RA) in daily practice in Canada $^{2}$. For this purpose, they took the opportunity to use data collected in the CATCH study (the Canadian Early Arthritis Cohort). The main conclusion of this elegantly conducted analysis is that the increase of treatment was strongly related to the physician's global assessment, whereas DAS28 was not.

The results have to be interpreted with regard to the following new paradigms in the management of RA, in particular at the early stage of the disease.

1. The current main objective of therapy with a disease-modifying antirheumatic drug (DMARD) in early RA is not only to improve the current symptomatic condition of the patient (e.g., level of pain, functional impairment, fatigue) but also to prevent any subsequent clinical handicap due to structural damage. Inflammation has been shown in different longitudinal epidemiological studies ${ }^{3,4,5}$ to be the major driving factor of such structural damage, whereas the intensity of the patient's symptom is correlated with the level of inflammation, but at a lower magnitude. Therefore, these preliminary remarks suggest that the initiation of DMARD should be based on objective signs of inflammation (number of swollen joints, acute-phase reactants) and not on the level of the patient's symptoms.

2 . The current evidence suggests that a treatment decision has to be taken if a predefined threshold in the level of disease activity is not achieved (the treat-to-target concept, $\mathrm{T} 2 \mathrm{~T})^{6,7,8}$.

3. Such evidence was mainly based on data observed in clinical trials in which the "level of disease activity" was evaluated using a composite index (the DAS28-ESR) combining physician-reported outcomes (number of swollen joints and erythrocyte sedimentation rate) and patient-reported out- come (patient's global assessment) and a mixed measure (number of tender joints). Such a composite index can be calculated by a research nurse prior to the visit of the patient with the rheumatologist ${ }^{9}$.

Therefore, an "artistic" approach can be defined by a decision taken by the rheumatologist integrating all the information available at the time of the visit (level of patient's symptoms and level of objective signs of inflammation but also comorbidities and history of patient's previous treatments) without considering any specific target to be reached.

At variance with this, an "artisan" approach can be defined by a decision by the rheumatologist mainly based on the a priori threshold of the tool permitting definition of an acceptable status from a physician's perspective (for example, a value of DAS28-ESR below 3.2).

In all the clinical trials comparing a "routine" or "artistic" approach versus an "intensive" or "artisan" approach" $10,11,12,13$, the "artisan" approach was superior to the "artistic" approach. Usually, the "artisan" approach is criticized for the following reasons:

1. The tool to evaluate the level of disease activity is not uniformly recognized (e.g., the DAS28-ESR ${ }^{1}$, the RAPID- $3^{14}$, no swollen joints at ultrasonography ${ }^{15}$ ). For example, in the study reported in this issue of The Journal ${ }^{1}$, the authors have noticed that the increase in treatments was not only based on the number of swollen joints but also the size of the joints affected by synovitis (larger joint involvement was more likely to influence treatment than number of swollen joints). 2. Such an approach does require perfect information/education of the patient at the initiation of treatment. To clearly understand this last statement we have to remember the different situations observed in daily practice (Table 1).

It is clear that the situations for which there is concordance between the patient and the doctor are easy to address - that is, no treatment in case of acceptable status (condition "a" in Table 1), or initiation of or reinforcing a DMARD in case of nonacceptable status (condition "d"). The 2 other conditions are more challenging.

See Increasing treatment in early RA: DAS vs MDGA vs PGA, page 2081 
Table 1. Definition of acceptable status. Patient's perspective: subjective symptoms (e.g., pain, functional impairment, fatigue). Doctor's perspective: objective signs of inflammation (e.g., synovitis, acute-phase reactants.

\begin{tabular}{lll}
\hline & \multicolumn{2}{c}{ Patient's Perspective } \\
& Yes & No \\
\hline Doctor's perspective & & \\
Yes & a & b \\
No & c & d \\
& & \\
\hline
\end{tabular}

Condition "b" is very well known by rheumatologists and can be attributed to either an advanced disease state with structural damage responsible for the patient's symptoms, a comorbidity such as fibromyalgia, or - and more difficult to address - a persistent active disease not recognized by the tools used by the physician, for example, normal C-reactive protein (CRP) and no swollen joints on physical examination.

Condition "c" is less frequent but also more problematic in daily practice. For example, in case of a lack of information/education in early RA, a patient who has dramatically improved after 8 to 12 weeks of treatment combining methotrexate and low-dose corticosteroids will be reluctant to accept initiation of another treatment such as a biologic because of the persistence of 6 swollen joints and a persistent increase in CRP.

Therefore, it seems that we have to reinforce the following points:

1. Accept using an "artisan" approach after "embarking" the patient in this approach via educational programs and with a clear definition of the target.

2. Continue to use an "artistic" approach since the decision to initiate/reinforce a treatment should consider not only the a priori defined target but also other variables such as comorbidities and history of previous treatments.

3. Conduct clinical trials evaluating the treatment effect of current DMARD in the 4 situations described in Table 1 , and in particular the treatment effect in the population of patients who consider themselves to have a nonacceptable status despite the lack of objective signs of inflammation.

\section{MAXIME DOUGADOS, MD,}

Paris-Descartes University, Department of Rheumatology B, APHP, Cochin Hospital, Paris, France

Address correspondence to Prof.Dougados; E-mail:m.doug@cch.aphp.fr

\section{REFERENCES}

1. van der Heijde D, van't Hof M, van Riel P, van de Putte L. Development of a disease activity score based on judgment in clinical practice by rheumatologists. J Rheumatol 1993; 20:579-81.
2. Pyne L, Bykerk VP, Boire G, Haraoui B, Hitchon C, Thorne JC, et al, for the CATCH Investigators. Increasing treatment in early rheumatoid arthritis is not determined by the Disease Activity Score but by physician global assessment: Results from the CATCH study. J Rheumatol 2012;39:2081-7.

3. Larsen A. The relation of radiographic changes to serum acute-phase proteins and rheumatoid factor in 200 patients with rheumatoid arthritis. Scand J Rheumatol 1988;17:123-9.

4. Van Leeuwen MA, van Rijswijk MH, van der Heijde DM, Te MG, van Riel PL, Houtman PM, et al. The acute-phase response in relation to radiographic progression in early rheumatoid arthritis: A prospective study during the first three years of the disease. Br J Rheumatol 1993;32 Suppl 3:9-13.

5. Welsing PM, van Gestel AM, Swinkels HL, Kiemeney LA, van Riel PL. The relationship between disease activity, joint destruction, and functional capacity over the course of rheumatoid arthritis. Arthritis Rheum 2001;44:2009-17.

6. Schoels M, Knevel R, Aletaha D, Bijlsma JW, Breedveld FC, Boumpas DT, et al. Evidence for treating rheumatoid arthritis to target: Results of a systematic literature search. Ann Rheum Dis 2010;69:638-43.

7. de Wit MPT, Smolen JS, Gossec L, van der Heijde DM. Treating rheumatoid arthritis to target: The patient version of the international recommendations. Ann Rheum Dis 2011;70:891-5.

8. Smolen JS, Aletaha D, Bijlsma JW, Breedveld FC, Boumpas D, Burmester G, et al. Treating rheumatoid arthritis to target: Recommendations of an international task force. Ann Rheum Dis 2010;69:631-7.

9. van Hulst LT, Fransen J, den Broeder AA, Grol R, van Riel PL, Hulscher ME. Development of quality indicators for monitoring of the disease course in rheumatoid arthritis. Ann Rheum Dis 2009;68:1805-10.

10. Grigor C, Capell H, Stirling A, McMahon AD, Lock P, Vallance R, et al. Effect of a treatment strategy of tight control for rheumatoid arthritis (the TICORA study): A single-blind randomized controlled trial. Lancet 2004;364:263-9.

11. Verstappen SM, Jacobs JW, van der Veen MJ, Heurkens AH, Schenk Y, ter Borg EJ, et al; Utrecht Rheumatoid Arthritis Cohort study group. Intensive treatment with methotrexate in early rheumatoid arthritis: Aiming for remission. Computer Assisted Management in Early Rheumatoid Arthritis (CAMERA, an open-label strategy trial). Ann Rheum Dis 2007;66:1443-9.

12. Fransen J, Moens HB, Speyer I, van Riel PL. Effectiveness of systematic monitoring of rheumatoid arthritis disease activity in daily practice: A multicentre, cluster randomized control trial. Ann Rheum Dis 2005;64:1294-8.

13. van Tuyl LH, Lems WF, Voskuyl AE, Kerstens PJ, Garnero P, Dijkmans BA, et al. Tight control and intensified COBRA combination treatment in early rheumatoid arthritis: $90 \%$ remission in a pilot trial. Ann Rheum Dis 2008;67:1574-7.

14. Pincus T, Furer V, Keystone E, Yazici Y, Bergman MJ, Luijtens K. RAPID3 (Routine Assessment of Patient Index Data 3) severity categories and response criteria: Similar results to DAS28 (Disease Activity Score) and CDAI (Clinical Disease Activity Index) in the RAPID 1 (Rheumatoid Arthritis Prevention of Structural Damage) clinical trial of certolizumab pegol. Arthritis Care Res 2011;63:1142-9.

15. Wakefield RJ, d'Agostino MA, Naredo E, Buch MH, Iagnocco A, Terslev L, et al. After treat-to-target: Can a targeted ultrasound initiative improve RA outcomes? Ann Rheum Dis 2012; 71:799-803.

J Rheumatol 2012;39:2064-5; doi:10.3899/jrheum.121086 